\title{
EDUCAÇÃO DO CAMPO: CONTEXTO E DESAFIOS DESTA POLÍTICA PÚBLICA
}

\author{
RURAL EDUCATION: \\ CONTEXT AND CHALLENGES OF A PUBLIC POLICY
}

\author{
Antonio Munarim \\ Geraldo Augusto Locks*
}

\begin{abstract}
Resumo: Este texto busca refletir o contexto do campo e das políticas de educação do campo de Santa Catarina. A reflexão se inspira em pesquisa conjunta realizada por pesquisadores da Universidade Federal de Santa Catarina e da Universidade do Planalto Catarinense. A expressão educação do campo, recente no Brasil, tem uma conotação político-pedagógica engendrada no Movimento Nacional de Educação do Campo para se distinguir do conceito educação rural, prevalecente na educação brasileira. A educação rural desconsidera a diversidade, especificidade e complexidade dos sujeitos que vivem e trabalham no campo. O Movimento de Educação do Campo procura reconhecer e fortalecer o processo de resistência e emancipação dos povos do campo na luta pelo direito a uma educação que lhes valorize as identidades. Contudo, quando se trata da operacionalização local das conquistas formais do movimento dadas no âmbito da União, emergem muitos desafios. Neste trabalho, priorizamos a análise sobre duas grandes ordens de desafios: o contexto cultural do campo e a operacionalização de uma política de Estado para garantir o direito à educação dos povos do campo. Em essência, no primeiro caso verifica-se que existe um ethos cultural no qual que se pode identificar diferentes valores e princípios que orientam escolhas, projetos de vida, concepções de espaço campo/cidade, que impactam profundamente, por exemplo, na sucessão das gerações nas unidades familiares. No segundo caso, além de limitações técnicas na gestão da coisa pública, a conformação político-jurídica do Estado brasileiro joga ao contrário da realização do direito social à educação.
\end{abstract}

Palavras-chave: Educação do campo. Contexto do campo. Política pública em Santa Catarina.

Abstract: This text discusses the rural context and Rural Education Policies in Santa Catarina, Brazil.
The discussion draws on joint research conducted by researchers from the Federal University of Santa
Catarina and the University of the Santa Catarina Plateau. The term "Education for Rural Populations",
a recent term in Brazil, has a politico-pedagogical connotation engendered in the National Movement
for Rural Education to distinguish it from the concept of "rural education”, which prevails in Brazilian
education. Rural education ignores the diversity, specificity and complexity of the subjects who live
and work in the countryside. The Movement for Rural Education seeks to recognize and strengthen the

* Doutor em Educação. Professor da Universidade Federal de Santa Catarina. Pós-doutorando do Programa de Pós-Graduação em Geografia da UNESP Campus Presidente Prudente. E-mail: <antoniomunarim@gmail.com >. * Doctor in Education. Professor at the Federal University of Santa Catarina. Postdoctoral student at the Post Graduate Programme in Geography at the UNESP. Presidente Prudente Campus. E-mail: < antoniomunarim@gmail.com>.

** Doutorado em Antropologia Social pela Universidade Federal de Santa Catarina. Pós-doutorando do PPGEUFSC. Professor da Universidade do Planalto Catarinense. E-mail: <geraldolocks@gmail.com>.

${ }^{* *}$ Doctor in Social Antrophology from the Federal University of Santa Catarina. Postdoctoral student at the PPGEUFSC. Professor at the University of the Plateau Catarinense. E-mail: <geraldolocks@gmail.com>. 
process of resistance and emancipation of rural populations who struggle for the right to education that enhances their identities. However, many challenges emerge when it comes to local implementation of the formal achievements of the Movement in the context of the Union. This paper gives special attention to the analysis of two main challenges: the cultural context of rural populations and the operationalization of a state policy to ensure the right to education of rural populations. Concerning the first challenge, it is observed that there is a cultural ethos in which one can identify different values and principles that guide choices, life projects, conceptions of space rural / urban, that have a big impact, for example, in the succession of generations in family units. In relation to the second challenge, it is observed that in addition to technical limitations in the management of public affairs, conformation of the political-legal Brazilian state acts in opposition to the social realization of the right to education.

Keywords: Rural Education. Rural context. Public policy in Santa Catarina / Brasil.

\section{Introdução}

Ainda tenho esperança. Com a educação do campo que conheci aqui neste encontro, não preciso mais ir embora para a cidade. (Camponês de Anita Garibaldi, SC).

Apresentamos neste texto, inicialmente, alguns aspectos que traçam um panorama geral da gênese e desenvolvimento da política pública da educação do campo no Brasil. Consideramos dois eventos como marcos simbólicos estruturantes na demarcação dos princípios para a construção do projeto político-pedagógico da educação do campo e, consequentemente, da constituição de sua política pública. O primeiro aconteceu em 1997, quando da realização do I Encontro Nacional de Educadores e Educadoras da Reforma Agrária (I ENERA), tido como o marco inicial do "Movimento Nacional de Educação Campo”. O segundo ocorreu em 2004, com a realização da II Conferência Nacional de Educação do Campo, que contou com a participação oficial do Ministério da Educação.

Com o primeiro marco, queremos demonstrar que a educação do campo, tanto do ponto de vista conceptual quanto do ponto de vista das principais ações conquistadas no interior do Estado brasileiro, resulta da construção histórica da sociedade civil organizada no campo, que pressiona o Estado e a própria escola diretamente, cujos professores, em regra, são tão refratários às inovações propostas por esses movimentos quão refratárias são as estruturas governamentais.

Com o segundo marco simbólico queremos demonstrar a tardia, mas, finalmente, entrada do Estado brasileiro a responder tais demandas de educação diferenciada para o campo. Com efeito, o espírito da Constituição de 1988, ao definir a educação como direito social e como direito público subjetivo, já apontava para a necessidade de os órgãos governamentais buscarem formas alternativas e diferenciadas para atender os diferentes na perspectiva da igualdade de oportunidade. Mais tarde, a LDB (Lei 9.394/96) é mais clara ao indicar a necessidade de atenção específica, por parte dos órgãos governamentais, à educação rural. E, por fim, uma série de acordos internacionais firmados pelo Governo brasileiro na área da educação define compromissos e tarefas assumidas por esse mesmo Governo, que incluem ações específicas direcionadas aos povos que vivem no campo. Não obstante tudo isso, somente a partir do início de 2003 é que o Governo da União, através do Ministério da Educação, começa a dialogar com os movimentos sociais do campo acerca da educação, e se 
encaminha, então, a realização conjunta da "II Conferência Nacional de Educação do Campo".

A expressão educação do campo é muito recente. $\mathrm{O}$ seu principal berço de origem é a luta pela terra, empreendida pelo Movimento dos Trabalhadores Rurais Sem Terra (MST), associada à demanda por escola pública em cada novo acampamento ou assentamento de reforma agrária. O que estamos aqui chamando de educação do campo foi cunhado em meados da década de 1990 e aparece pela primeira vez em documento oficial normativo somente no ano de 2008. O termo tem uma conotação político-pedagógica para se distinguir da educação rural até então reinante nas diretrizes educacionais e nos marcos legais reguladores da educação brasileira. A educação rural na história educacional brasileira até então foi concebida e operacionalizada genericamente, sendo desconsideradas características como diversidade, especificidade e complexidade dos sujeitos que vivem e trabalham no campo. Foi a Resolução CNE/CEB n ${ }^{\circ} 1$, de 3 de abril de 2002, que instituiu as primeiras Diretrizes Operacionais para a Educação Básica nas escolas do campo no Brasil, reconhecendo o modo próprio de vida social, a utilização do espaço do campo em sua diversidade, onde vivem cidadãos com uma identidade específica. Em seu art. $2^{\circ}$, parágrafo único, pela primeira vez, encontra-se a preocupação pela definição da identidade da escola do campo:

A identidade da escola do campo é definida pela sua vinculação às questões inerentes à sua realidade, ancorando-se na temporalidade e saberes próprios dos estudantes, na memória coletiva que sinaliza futuros, na rede de ciência e tecnologia disponível na sociedade e nos movimentos sociais em defesa de projetos que associem as soluções exigidas por essas questões à qualidade social da vida coletiva no país. (Resolução CNE/CEB n 1, de 3 de abril de 2002).

Portanto, encontra-se consignado no marco legal da educação do campo o reconhecimento de uma escola com uma identidade própria, devendo-se considerar em sua prática educativa a realidade dos estudantes, espaço e tempo, necessidades e interesses, seus saberes e fazeres. Evidentemente, a caracterização de uma identidade específica implica a compreensão do papel da escola e do educador, na reconfiguração curricular, conteúdos adequados, metodologias correspondentes, formação pedagógica apropriada dos professores, material didático, infraestrutura e planejamento descentralizado, garantindo a educação e a qualidade de vida dos povos do campo ${ }^{1}$.

Deve ser enfatizado, todavia, que a diretriz acima explicitou a identidade escolar vinculada aos movimentos sociais. Ou seja, na proposição político-pedagógica da educação do campo compreende-se que ela não se encerra na escola. A aprendizagem e a produção de saberes ocorrem em outros espaços não formais. Sustenta-se, pois, uma concepção ampla de educação, em que a escola além de cumprir finalidades específicas - é um espaço estratégico de luta social e de vinculação com outras práticas sociais e projeto de desenvolvimento do campo e de sociedade. Outro aspecto a ser considerado nesse panorama geral são as etapas e quem são os destinatários da educação do campo. O art. $1^{\circ}$ da Resolução n ${ }^{\circ} 2$, de 2008, do CNE/CEB, instituída em abril de 2008, afirma que

\footnotetext{
1 Caberia aqui consignar que as Diretrizes Operacionais para a Educação Básica nas Escolas do Campo se fez objeto de trabalho, junto ao Conselho Nacional de Educação (CNE), não por iniciativa do MEC, como seria a praxe, mas por ação direta de movimentos sociais do campo, que pressionaram aquele Conselho. Ademais, aprovadas as Diretrizes no âmbito do CNE, o MEC manteve-se imóvel quanto à sua consequência prática até o advento do Governo Lula.
} 
A Educação do Campo compreende a Educação Básica em suas etapas de Educação Infantil, Ensino Fundamental, Ensino Médio e Educação Profissional Técnica de nível médio integrada com o Ensino Médio e destina-se ao atendimento às populações rurais em suas mais variadas formas de produção da vida - agricultores familiares, extrativistas, pescadores artesanais, ribeirinhos, assentados e acampados da Reforma Agrária, quilombolas, caiçaras, indígenas e outros. (Resolução CNE/CEB, $n^{\circ} 2$, de 28 de abril de 2008).

Para além do direito à universalização da educação formal em todas as etapas, o Movimento Nacional da Educação do Campo procura reconhecer e fortalecer o processo de resistência e emancipação dos povos do campo. Afirma a diversidade de formas de produção da vida nas quais todos os sujeitos sociais sejam contemplados no direito ao acesso e à qualidade de educação em todos os níveis. Nesse processo preconiza-se uma educação “no campo”, porque o povo tem o direito de ser educado onde vive; “do campo", porque o povo tem direito a uma educação pensada desde o seu lugar e com a sua participação, e que seja vinculada a sua cultura e as suas necessidades. Esta nova concepção de educação, dentre seus princípios, se direciona no sentido da construção da identidade e autonomia das populações do campo. Sustenta o entendimento da relação de complementaridade no binômio campo-cidade, onde uma faceta não vive sem a outra. Desse modo, a educação escolar deve evitar tanto a visão urbanocêntrica quanto o ruralismo. São princípios pedagógicos defendidos por esse Movimento que as práticas educativas nas escolas devem levar em conta o contexto dos sujeitos do campo, em termos de sua cultura específica, a maneira de ver e se relacionar com o tempo, o espaço, o meio ambiente, e o modo de viver e de organizar o trabalho.
É preciso, todavia, consignar que não obstante esses avanços de organização social, política e de estabelecimento de princípios pedagógicos, a concepção e, principalmente, a operacionalização da educação do campo no Brasil não estão concluídas, tampouco consolidadas. Aqueles que estão interessados no debate, autores ou outros sujeitos envolvidos na prática e na discussão teórica, convergem para o fato de que o conceito de educação do campo não poderá ser fixado ou engessado em um conjunto de palavras.

Por último, do ponto de vista da regulamentação, o movimento social da educação do campo inseriu outras preocupações a serem assumidas pelo sistema educacional, além do que está previsto nas "Diretrizes Operacionais”, que foi o primeiro, e continua sendo o principal documento normativo. Essas preocupações foram privilegiadas na Resolução $n^{\circ} 2$, de abril de 2008, que considerou aspectos como a responsabilidade dos três entes federados, principalmente o fechamento de escolas, a nucleação de escolas e o transporte escolar. A última conquista do Movimento Nacional de Educação do Campo no escopo das políticas públicas brasileiras $^{2}$ materializou-se no Decreto Presidencial $\mathrm{n}^{0} 7.352$, de 4 de novembro de 2010, no qual são retomados os princípios da educação do campo e os compromissos dos entes federados. Esse decreto dispõe sobre a oferta de Educação Básica e Superior às populações do campo, alarga o leque dos destinatários e define os critérios para se identificar a escola do campo.

\footnotetext{
${ }^{2}$ No momento da conclusão do presente texto encontra-se tramitando no Congresso Nacional a Medida Prosória n. 562, de março de 2012, quepropõe a criação do Programa Nacional de Educação do Campo (PRONACAMPO), No ensejo de concretizar determinações do Decreto n. 7.352, esse Programa deverá contemplar, em certa medida. as proposições do Movimento Nacional de Educação do Campo; mas, ainda trata-se de um "vir a ser".
} 
Decorrida mais de uma década de luta social pela construção da política pública da educação do campo, perguntamos: a constituição de um marco legal garante a efetividade da educação do campo? A existência de Fóruns nacional, estaduais e regionais, a participação de Universidades públicas, o compromisso efetivo de alguns setores do governo na esfera federal e de alguns governos locais no campo da educação, do desenvolvimento social e da reforma agrária, a persistência do movimento social ainda não garantem a efetivação das Diretrizes Operacionais para a Educação Básica nas Escolas do Campo. Tampouco asseguram o cumprimento das duas outras normas subsequentes acima referidas - a Resolução CNE/CEB n ${ }^{\circ}$ 2, de 2008, e o Decreto $\mathrm{n}^{0}$ 7.352, de 2010. O que temos presenciado, ao invés, e nossos estudos assim o demonstram, é a continuidade da precarização da educação nos contextos rurais, cuja principal solução tem sido o fechamento de escolas e o contraposto transporte dos alunos de todas as idades para que se cumpra o estatuto da escolarização obrigatória ${ }^{3}$.

Tendo presente o panorama da gênese da educação do campo no âmbito do estado nacional brasileiro e da nação brasileira, âmbito no qual se forjam as grandes concertações que resultam nas normativas gerais, centramos nossa atenção agora nos desafios que emergem quando se trata da operacionalizar a política pública da educação do campo nos âmbitos locais, mais propriamente do estado federado e dos municípios. Santa Catarina é nossa referência empírica. Nesse

\footnotetext{
${ }^{3}$ Nos últimos oito anos, mais de 24 mil escolas do campo foram fechadas em todo o Brasil. Os dados do Censo Escolar do Instituto Nacional de Estudos e Pesquisas Educacionais (INEP), do Ministério da Educação, apontam que, no meio rural, existiam 107.432 escolas em 2002. Já em 2009, o número de estabelecimentos de ensino reduziu para 83.036. Ver: www.mst.org.br Fechar Escola é Crime. (Acesso em: 19/10/2011).
}

estado da federação temos estudado as políticas e práticas empreendidas pelo Governo do Estado e focado nossas atenções sobre os 18 municípios que compõem a Região Serrana, ou Planalto Catarinense, ou Território da Serra - as denominações, enfim, são fluidas, como fluidas são as fronteiras que determinam e conceituam um território: econômicas, culturais, sociais, políticas, ambientais, etc. Para efeitos desta reflexão, nossa atenção se concentra nos vieses da cultura e da ação política, sem deixar de compreender as determinações econômicas estruturais nos caminhos e, principalmente, nos descaminhos da educação do campo.

Com efeito, nossos estudos nos levam a perceber a existência de uma trama de óbices à concretização das conquistas formais do Movimento Nacional de Educação do Campo, que extrapolam as evidências explícitas e as razões mais aparentes e, conforme concluídos, de difícil superação.

\section{O contexto cultural do campo e a re- sistência à educação do campo}

Partimos do pressuposto de que existe um ethos cultural no universo do campo a ser reconhecido e considerado. Estamos utilizando o termo no mesmo sentido atribuído pelo antropólogo Gregory Bateson (cf. GOMES, 2008), quando, na década de 1930, tentou explicar a singularidade do modo de sentir o mundo e de se comportar de acordo com princípios, normas e valores reconhecidos pelo povo Iatmul, das ilhas Samoa, onde ele fazia pesquisas de campo.

Bateson estava interessado em compreender como os sujeitos vivenciavam o sentido de ser no mundo, e como essa vivência expressava valores e normas. Ou seja, ethos passou a ser uma palavra útil para explicar a subjetividade da cultura, assim como 
para identificar diferentes valores e princípios que orientam escolhas, projetos de vida, concepção de espaço (neste caso, campo/ cidade), concepção de bem-estar, qualidade de vida, que impactam profundamente, por exemplo, na sucessão das gerações nas unidades familiares e na tomada de decisões técnicas, pedagógicas e políticas relativas à educação do campo.

É sabido que o campo brasileiro vem sendo reconfigurado constantemente, dificultando a identificação de um ethos que expresse exclusivamente o meio rural, sem relacioná-lo com o espaço urbano. Os espaços de moradia, as atividades econômicas, a interação de serviços e, inclusive, as relações de parentesco hoje fazem do campo/cidade espaços específicos e complementares.

O ethos cultural é estabelecido por distintos sujeitos sociais, homens e mulheres que produzem suas vidas no campo, por agentes de Estado promotores de políticas públicas no campo, e até mesmo pela grande mídia formadora de opinião pública. Nosso ponto de partida de análise do contexto cultural do campo implica uma visão sobre a totalidade, o movimento e as contradições na realidade do modo capitalista de produção da existência. Segundo Caldart,

A educação do campo nasceu como crítica à realidade da educação (....) essa crítica nunca foi à educação em si mesma porque seu objeto é a realidade dos trabalhadores do campo, o que necessariamente a remete ao trabalho e ao embate entre projetos de campo que têm consequências sobre a realidade educacional e o projeto de país. (CALDART, 2010, p. 106).

Portanto, o ethos cultural do campo é expressão do modo como a realidade social, econômica, política, estética, educacional, cidadã do campo foi historicamente construída, experimentada e revelada pelos sujeitos sociais. Precisamos também nos dar conta, como adverte Frigotto (2010, p. 39), “de que somos herdeiros de uma cultura escravocrata, autoritária e repleta de preconceitos vincados ao núcleo constituinte das sociedades de classe". Nesse sentido, o primeiro aspecto que desejamos destacar é a concepção do binômio indissociável campo/cidade.

O primeiro preconceito que emerge na representação espacial do campo é a imagem do "lugar do atraso, do subdesenvolvimento”, sendo sua face oposta, a cidade, como o "lugar do moderno, do progresso". Esse estigma tem, entre outras, sua externalidade na imediata aprovação dos pais de alunos e no interesse deles diante do transporte escolar oferecido pelo sistema educacional público. Uma vez fechada uma determinada escola do campo, seu corolário é a oferta do transporte escolar dos alunos para a sede do município. Acessar um veículo para transporte coletivo, dirigir-se à sede do município, estudar em uma escola localizada no espaço urbano significa status, prestígio, ascendência social para muitos sujeitos sociais diante da sociedade. Há uma lógica nessa visão diante da ideologia que sustenta a superioridade hierárquica da cidade sobre o campo, inculcada pela literatura, pela indústria cultural, pelos meios de comunicação e, enfim, pela opinião pública.

Nos últimos cinco anos, algumas Secretarias Municipais de Educação de nosso campo empírico passaram a conhecer e efetivar algumas orientações das Diretrizes Operacionais da Educação do Campo. Ao avaliarem equívocos em sua política de educação para o meio rural, começaram a implementar escolas nucleadas com deslocamento dos alunos, não mais para o meio urbano, mas intracampo, conforme prevê a Resolução do CNE/CEB n ${ }^{\circ} 2$, de abril de 2008. Paradoxalmente, gestores educacionais encontraram resistência por parte dos pais, conforme 
relata uma Secretária Municipal, “exigindo a continuidade do estudo de seus filhos na sede do município", ao custo de verem a continuidade da escola do campo fechada ${ }^{4}$, de relegarem seus filhos ao transporte escolar precarizado, às longas viagens diárias de ida e volta, saindo de madrugada e chegando no meio da tarde, à perda da convivência familiar, ao abandono da cultura do trabalho no campo e a tantos outros problemas.

Sem dúvidas, percebemos também posição inversa a essa resistência, sendo útil para se compreender a complexidade e as contradições em que a educação do campo se encontra envolvida. Ou seja, há segmentos sociais no campo, mormente formados por aquelas pessoas que de alguma forma se vinculam e/ou militam em algum tipo de movimento de direitos de cidadania, que compreendem e acreditam que se a escola do campo for contemplada de condições adequadas, terá valor igual ou superior ao que as melhores escolas urbanas já alcançaram. No discurso desses segmentos está o entendimento de que fechar uma escola do campo pode significar privar milhares de jovens do direito a uma educação que se dê em sua realidade e como parte de sua cultura. Contudo, a visão dicotômica, de subalternidade da cidade sobre o campo, nos parece evidentemente hegemônica. Há muitos municípios, a maioria, em que não há nem sinal da existência de qualquer movimento ou organização social no campo a defender os princípios da educação do campo. Ademais, cabe afirmar que nossas observações registram que, em regra, os gestores da educação nos municí-

\footnotetext{
${ }^{4}$ Houve um caso extremo e emblemático em que os pais acionaram o Ministério Público para exigir da Prefeitura Municipal o transporte para seu filho estudar em escola da cidade, rejeitando a escola pública municipal que lhe oferecia vaga em frente a sua casa, sob alegação do “direito de escolha”. E o Promotor Público aceitou essa alegação.
}

pios estão embebidos da mesma perspectiva ideológica, ou do mesmo ethos que indica a subalternidade do campo à cidade e, portanto, são convencidos do acerto em se transportar as crianças e jovens para que estudem em escolas da cidade.

Um segundo aspecto para análise do ethos cultural do campo é a juventude que ainda vive no campo ou que compõe os reconhecidos povos do campo nas suas mais variadas formas de produção da vida, como agricultores familiares, extrativistas, pescadores artesanais, ribeirinhos, assentados e acampados da Reforma Agrária, quilombolas, caiçaras, indígenas e outros. Na perspectiva da diversidade de sujeitos sociais já não podemos mais nos referir à juventude no singular, mas às “juventudes” do campo, pois em cada variada forma de produção da vida vão se encontrar jovens orientados por lógicas culturais específicas.

Um jargão repetido em Santa Catarina é que a partir dos anos de 1970, do ponto de vista populacional, o Campo vem sendo progressivamente empobrecido, envelhecido, aposentado e esvaziado. Considerando o universo diverso dos sujeitos que ainda vivem no campo, a juventude é quem mais vive a tensão, o drama de logo ter que decidir onde viver. Diante da realidade vivida no campo, dos valores e símbolos produzidos pelo imaginário urbano, não tem dúvida em decidir por “ir embora” para a cidade. É preciso lembrar que a maioria dos jovens do campo de Santa Catarina não tem acesso em sua realidade ao Ensino Médio e à Educação Profissional Técnica integrada com o Ensino Médio. Excluídos do acesso à educação de nível médio, sem qualificação profissional que lhes permita a reprodução da existência, obrigam-se a escolher a cidade e abandonar a família e o campo. Disso resulta um novo problema de ordem estrutural no campo - a sucessão geracional, a transferência de poder 
e de patrimônio entre as gerações que se sucedem na unidade familiar camponesa.

O II Seminário Catarinense de Educação do Campo, realizado em Florianópolis, nos dias 19 a 21 de maio de 2010 (FOCEC, 2010), trouxe para o debate, entre outras, as perguntas: "quem irá suceder a atual geração que vive e trabalha no campo?” Entre os jovens camponeses, "quem deseja suceder seus pais"? ”De quem é a responsabilidade de criar as condições para que a sucessão ocorra de maneira regular, emancipatória, respeitando a autonomia e as responsabilidades sociais dos diferentes sujeitos envolvidos? Contidas no documento final, as respostas às questões apontam para um horizonte sombrio em que se confirma o processo de êxodo de jovens. A partir das vozes desse seminário, podemos afirmar que a juventude do campo não tem autonomia, não se percebe capacitada profissionalmente, não encontra alternativa e nem oportunidades para escolher o campo como espaço de vida, desenvolvimento humano e cidadania. A juventude ainda presente no campo, sem poder de escolha, mas empurrada para o meio urbano, não se sente com poder para exigir dos entes responsáveis a educação que lhe seja adequada e atenda seus interesses, na perspectiva da vida no campo. De toda sorte, o tema tem assumido importância e está na agenda de diferentes instituições governamentais e não governamentais, pois as comunidades rurais catarinenses sofrem verdadeira erosão social. Reafirma-se a urgência de educação escolar no campo, condizente com os novos tempos e com as novas conformações das ruralidades; mas, ao que podemos interpretar, essas vozes não são tão consistentes e crentes dessa possibilidade. Mais parecem repetição de clichês que caem no vazio. Exemplo disso está no fato de o documento final do referido Seminário, que aponta elementos para uma diretriz estadual de educação do campo, ter estacionado numa sala qualquer da Secretaria de Estado da Educação e, desde então, nada mais se moveu.

Diante do desafio da sucessão das gerações no campo, a reflexão de Molina torna-se extremamente oportuna:

Um dos maiores desafios postos à continuidade das lutas pelas Políticas Públicas de Educação do Campo são as lutas pela permanência do campo e de todas as suas contradições no centro dessas políticas, o que só se fará com a permanência dos sujeitos que as protagonizam em suas vidas e lutas cotidianos se reproduzindo como sujeitos camponeses. (MOLINA, 2010, p. 143).

O que está latente na dificuldade da permanência e da reprodução dos sujeitos camponeses, incidindo de maneira particular sobre os jovens, é a estrutura de poder e de dominação. Na impossibilidade de reprodução social da família camponesa reside o maior desafio estrutural da vida e do desenvolvimento do campo imposto pelo modo de produção capitalista. Isso se revela na disputa pela ocupação do espaço e das atividades produtivas no campo, como ocorre pelo país afora, incluindo Santa Catarina, onde é visível o agronegócio e a agricultura familiar se constituírem polos antagônicos de tal conflito. Enfim, o desafio apontado por Molina é maior do que pode parecer à primeira vista. Ou seja, no limite, a educação do campo encontra-se no centro de uma luta de hegemonia de projetos históricos de sociedade, onde se tem de optar por um ou por outro modelo de desenvolvimento de campo. E diante dessa encruzilhada, os jovens do campo em geral têm, de um lado, um Estado estruturalmente comprometido com as forças hegemônicas do capital, para o qual importa, antes de tudo, uma educação escolar que seja funcional ao sistema hegemônico. As poucas conquistas em termos de normativas 
no escopo do Estado Nacional durante o Governo Lula e o fato de estarem todas elas, desde que nasceram até o presente, relegadas à situação de letra morta só confirma essa assertiva. De outro lado, esses jovens têm um arcabouço conceitual de outra educação, inclusive escolar, que promete a emancipação humana, mas que sofre a reação silenciosa e virulenta do ethos cultural da subalternidade do campo e padece de fragilidade física no campo da luta política, no qual são escassos os dirigentes e os militantes.

$\mathrm{O}$ terceiro aspecto que privilegiamos neste texto na ordem dos desafios no contexto cultural do campo que tomamos como referência empírica é a presença da diversidade étnico-racial no campo. Santa Catarina é um estado com presença da maioria dos segmentos sociais que configuram os povos do campo no Brasil. Indígenas, caboclos, cafusos, afrodescendentes, descendentes do sul, centro e leste europeu (açorianos, espanhóis, alemães, italianos, poloneses, lituanos, sírio-libaneses), a colonização japonesa vinda do Oriente constituem as comunidades no campo. É sabido que cada identidade étnica remete para um universo cultural, compartilha valores, visões de mundo, sentido do trabalho, vínculos de pertencimento e comunicação entre seus membros.

Os gestores da educação de nosso espaço de pesquisa no Planalto Catarinense afirmam que questões como a valorização da educação, o engajamento na afirmação da escola no campo, a continuidade e o significado de estudar tendo em vista a formação humana, cidadã e profissional têm variantes de etnia para etnia. Tratar homogeneamente todas as etnias no desenvolvimento da política pública da educação do campo seria também um anacronismo, uma vez que o fenômeno exige a aplicação de diferentes estratégias de sensibilização, mobilização e pró-atividade na garantia do protagonismo de todos os sujeitos presentes no campo. De outro lado, na sua origem, a educação do campo nasceu das lutas sociais do campo. Nem todos esses segmentos étnicos acham-se envolvidos em lutas sociais. Como, enfim, trabalhar a educação do campo considerando as diferentes identidades étnicas e seus respectivos envolvimentos ou não com as lutas sociais? Se o campo tem sua identidade enquanto espaço, nele vivem sujeitos sociais com diferentes identidades culturais, e para a educação do campo torna-se um imperativo seu reconhecimento e seu tratamento político-pedagógico.

\section{Outros desafios políticos à educação do campo}

Até aqui, tentamos desvendar barreiras que se interpõem à educação do campo advindas do próprio ethos cultural daqueles que seriam supostamente os seus beneficiários. Percebemos que existem barreiras estruturais, assentadas em última instância no modo capitalista de produção, as quais, no processo e ao cabo, se servem e ao mesmo tempo reforçam o ethos cultural da subalternidade dos povos do campo, de modo a resistirem a um projeto de educação emancipatória. Para entrar numa outra linha de visualização de limites à realização da educação do campo, de cunho mais político, importa trazer à tela, inicialmente, a reafirmação de que educação do campo é entendida aqui numa perspectiva conceitual de emancipação humana irrestrita. Como tal, é menos um conjunto de métodos e técnicas didáticas e político-pedagógicas que se aplicam eventualmente nas escolas públicas concretas, mas que delas se serve para seguir no rumo do horizonte de sua própria construção. Equivale a dizer que, na luta de hegemonia, mesmo sendo, e devendo ser, pessimistas na análise, os sujeitos da luta contra-hegemônica não 
abandonam a perspectiva otimista do horizonte que se realiza nas pequenas conquistas do processo.

Para os limites deste texto, priorizamos apontar uma barreira de ordem político-institucional que, a nosso ver, a par de frear avanços em toda a educação pública obrigatória no Brasil, emperra particularmente a educação do campo. Estamos falando do pacto federativo, que cria o chamado regime de colaboração para que o Estado brasileiro, por meio de suas três esferas, cumpra o dever de garantir a educação escolar definida como obrigatória.

Nesse pacto, cabe prioritariamente ao poder local, isto é, à prefeitura municipal, garantir a oferta da educação escolar para as crianças do nível fundamental, que vai até os 14 anos; e aos estados cabe o ensino médio e profissional, prioritariamente. Ademais, salvaguardadas as diretrizes nacionais para as etapas e modalidades, em geral suscetíveis de interpretações ambíguas e interesseiras, cada ente federado tem ampla liberdade de movimento garantida no estatuto do pacto. Para o caso da educação, portanto, em vez de um sistema único, há o sistema federal, as dezenas de sistemas estaduais - um para o Distrito Federal e um para cada estado e os milhares de sistemas municipais de educação.

Ora, conforme vimos acima, o ethos cultural dos povos do campo nos municípios analisados, que engloba os próprios gestores municipais de educação, aponta para direção contrária às conquistas do Movimento Nacional de Educação do Campo, já consignadas nas normativas oficiais, indicando comumente a preferência pelo transporte para escolas do meio urbano. Ademais, se os gestores municipais não agem por crença própria de que oferecer escola urbana às crianças e jovens rurais é o melhor que têm a fazer no cumprimento do seu papel de servidor público o fazem por conveniência política no mercado das trocas clientelistas muito próprias do poder local. Ou, ainda, o fazem conduzidos por uma racionalidade eminentemente econômico-financeira de barateamento dos custos dos serviços executados pelo município, que, via de regra, conta com parcos recursos para a área educacional. Assim, as exceções, que podem ser enquadradas como experiências municipais de boas práticas de educação nos contextos rurais, devem ser encaradas como referências não para justificar a pulverização dos sistemas, mas sim para indicar como se pode agir nos diversos locais, desde o centro do poder, na perspectiva de um único sistema nacional integrado de educação. Como exemplo de outros países, bastaria prestar atenção ao que vem ocorrendo na Argentina que, nos últimos anos, tem processado uma reconcentração da ação do Estado Nacional na área da educação. Só para sinalizar, o país vizinho, que, diferentemente do Brasil, não conta com a força de movimentos e organizações sociais do campo a lutar por uma educação diferenciada aos povos do campo, tem, no entanto, uma recente "diretriz operacional para a educação" ${ }^{5} \mathrm{e}$ um correspondente conjunto de programas, projetos e estrutura de gestão oficiais em andamento, que perseguem de maneira efetiva o objetivo da universalização da educação como direito humano, tal como consignado nos acordos internacionais dos quais a Argentina, e também Brasil, fazem parte.

Por fim, colada às dificuldades impostas pelas condições político-institucionais da descentralização, percebemos, tanto por parte de gestores quanto de educadores de escolas do campo, uma ordem de dificuldade

\footnotetext{
${ }^{5}$ Referimo-nos à Resolución CFE No $128 / 10$ e ao seu anexo "Educación Rural en el Sistema Educativo Nacional".
} 
que se situa no âmbito pedagógico e da organização escolar. Afinal, quando referida de maneira restrita à escola, a educação do campo constitui, ou quer se constituir como um modelo especial de educação? Ou bastaria replicar os bons exemplos de escola pública urbana com as devidas adequações aos contextos rurais respectivos?

Nós não temos dúvida de que, sob a perspectiva da educação do campo, a educação escolar nos contextos rurais deve constituir uma modalidade específica de educação. Mas hoje, ainda que formalmente o Conselho Nacional de Educação permita ${ }^{6}$, pelas práticas que conhecemos, não constitui. Mais uma vez, temos a aprender com a vizinha Argentina, que oficialmente - e para todas as consequências - declara a educação rural como uma modalidade própria para todos os níveis da educação obrigatória. Isso tem proporcionado liberdade e desafiado os agentes das ações educativas a buscarem maneiras, as mais criativas, para atender a todas as comunidades isoladas e pessoas em idade escolar, estejam onde estiverem. Outro exemplo, embora restrito à educação primária, que vai dos 6 anos até os 12 anos, e embora não definido em lei ou normativa como modalidade específica, é o que vimos na Comunidade Autônoma da Catalunha.

Com experiência consolidada na prática de várias décadas sob a orientação do Movimento de Renovação Pedagógica da Catalunha, no qual os "maestros rurales" têm sido presença efetiva, massiva e organizada, a educação rural dessa Comunidade Autônoma se sobressai, comparativamente, em todas as avaliações, seja em forma de índices oficiais, seja em análises acadêmicas.

\footnotetext{
${ }^{6}$ A "Resolução no 4 CNE/CEB, de 13 de julho de 2010", que "define as Diretrizes Curriculares Nacionais Gerais para a Educação Básica”, ainda que indiretamente, classifica a educação do campo como modaliade.
}

É certo que, no Brasil, carecemos de certas condições históricas existentes na Catalunha e que são imprescindíveis. Destacamos, particularmente, a forte organização social dos docentes rurais e a efetividade do conceito de "pueblo educador", pelo qual se distingue uma cultura de engajada participação da comunidade educativa, que engloba todos os habitantes, na vida da pequena e única escola do povoado. Mas a Catalunha tem uma decisão política em execução, advinda da sociedade catalã e de seus sucessivos governos, que teria de ser copiada pelo Brasil antes que, também a exemplo deles, tenhamos que fazê-lo para correr atrás do prejuízo. Referimo-nos às definições orçamentárias concernentes à educação escolar rural. Para simplificar, segundo informa o Departamento de Educação da Generalitat de Barcelona, o custo-aluno-ano da escola rural é três vezes mais em comparação à escola urbana. Por que se dispõe a pagar tal custo? Resposta imediata da mesma representante do Departamento de Educação: porque é necessário investir na recuperação do equilíbrio territorial, perdido que foi ao longo das últimas três décadas, em consequência de projetos econômicos e de políticas públicas que promoveram o esvaziamento do campo em nome da modernização. Em outra resposta, esta colhida de uma diretora de uma escola rural, diz-se que à escola rural na Catalunha, de maneira precípua, cabe a tarefa de garantir a (re) construção das identidades locais e da identidade catalã, diante da diversidade de imigrantes advindos de outros países para suprir a lacuna de mão-de-obra, e diante do fenômeno recente dos chamados "neo-rurais", que preferem as escolas rurais

\footnotetext{
${ }^{7}$ Vem ocorrendo na Catalunha um fenômeno de retorno ao campo. Pessoas que deixam total ou parcialmente os centros urbanos para viver nos "pobles” e mesmo em sítios antes abandonados. São os “neo-rurais”, que buscam melhor qualidade de vida a custos mais baixos,
} 
como garantia de qualidade na educação de seus filhos. Ora, com tais atribuições que lhe são dadas, e com tal "ethos cultural”, é fácil de se supor que essa escola tem de ser especial e, para isso, carece de financiamento também especial. Acreditamos não ser um despropósito inferir que o custo-aluno-ano não precisaria ser comparativamente tão alto na situação da Catalunha, caso tivesse aquela sociedade tomado consciência antecipada do processo de desequilíbrio que se vivia na relação campo-cidade.

Enfim, a educação do campo em Santa Catarina e por todo o país, em sua gênese, no que concerne à sociedade e ao Estado, fez um percurso notável. Da parte da sociedade civil organizada, concepção, princípios, um novo olhar para o campo e para a educação do campo podem ser anotados como conquistas. Do lado do Estado, por pressão social, foi estabelecido um conjunto normativo que, desafortunadamente, não garante operacionalização desta política pública. Como vimos, o Estado capitalista não tem interesse em inverter a ordem vigente do campo. Portanto, existe um longo caminho com muitos desafios a ser enfrentado pelo protagonismo de uma sociedade e de um Estado em processo de democratização.

\section{Referências}

BRASIL. Resolução CNE/CEB n. 1, de 3 de abril de 2002. Institui Diretrizes operacionais para a Educação Básica nas escolas do campo. Disponível em: < http://portal. mec.gov.br/cne/arquivos/pdf/CEB012002. pdf $>$. Acesso em: 23 fevereiro 2011.

\section{Resolução n. 2, de 28 de abril de}

e um dos principais itens é exatamente a escola rural, cuja condição para matricular o filho é viver na comunidade.
2008. Estabelece diretrizes complementares, normas e princípios para o desenvolvimento de políticas públicas de atendimento da Educação Básica do Campo. Disponível em: < http://portal.mec.gov.br/cne/arquivos/ pdf/2008/rceb002_08.pdf $>$. Acesso em: 23 fevereiro 2011.

. Resolução n. 4, de 13 de julho de 2010. Define Diretrizes Curriculares Nacionais Gerais para a Educação Básica. Disponível em: <http://www.ca.ufsc.br/files/2012/05/rceb004_10.pdf>. Acesso em: 23 fevereiro 2011.

. Resolução n. 2, de 28 de abril de 2008. Estabelece diretrizes complementares, normas e princípios para o desenvolvimento de políticas públicas de atendimento da Educação Básica do Campo. Disponível em: $<$ http://portal.mec.gov.br/arquivos/pdf/resolucao_2.pdf $>$. Acesso em: 23 fevereiro 2011.

Decreto n. 7.352, de 4 de novembro de 2010. Dispõe sobre a política de educação do campo e o Programa Nacional de Educação na Reforma Agrária - PRONERA. Disponível em: <http://www.planalto. gov.br/ccivil_03_/Ato20072010/Decreto/ D7352.htm>. Acesso em: 23 fevereiro 2011.

CALDART, R. S. Educação do campo: notas para uma análise de percurso. In: MOLINA, M. C. (Org.). Educação do campo e pesquisa II: questões para reflexão. Brasília: MDA/MEC, 2010.

FOCEC. Bases para a construção das diretrizes operacionais para a educação do campo de Santa Catarina: construção coletiva do Fórum Catarinense de Educação do Campo (FOCEC). Instituto de Educação do Campo e Desenvolvimento Territorial Sustentável - Educampo / UFSC, 2010.

FRIGOTTO, G. Projeto societário contra-hegemônico e educação do campo: de- 
safios de conteúdo, método e forma. In: MUNARIM, A.; BELTRAME, S.; CONTE, S. F.; PEIXER, Z. I. (Orgs.). Educação do campo: reflexões e perspectivas. Florianópolis: Insular, 2010.

GOMES, M. P. Antropologia: ciência do homem; filosofia da cultura. São Paulo: Contexto, 2008.

MOLINA, M. C. Reflexões sobre o significado do protagonismo dos movimentos sociais na construção de políticas públicas de educação do campo. In: . (Org.). Educação do campo e pesquisa II: questões para reflexão. Brasília: MDA/MEC, 2010.

Recebido em: 03/05/2012

Aceito em: 08/06/2012 